\title{
Nuevos documentos sobre tipografía murciana del siglo XVIII
}

\author{
Amparo GARCÍA CUADRADO \\ Universidad de Murcia. Departamento de Información y Documentación \\ ampagar@um.es
}

\begin{abstract}
Recibido: junio 2011
\end{abstract}
Aceptado: octubre 2011

\begin{abstract}
Resumen: En junio de 1788 los impresores Manuel Muñiz y Antonio de Santa María tomaban la decisión de asociarse creando la primera imprenta mancomunada de que tenemos noticia en la ciudad de Murcia. Un mes más tarde pasaban por el registro de Francisco Bocio con objeto de formalizar la compañía y establecer las condiciones por la que debían gobernarse. Las informaciones que aportan este documento y otras diversas escrituras acerca del devenir del taller del Plano de San Francisco permiten alumbrar un tramo de historia de la tipografía murciana del Setecientos.
\end{abstract}

Palabras clave: Imprentas del siglo XVIII; Talleres murcianos; Compañía de impresores; Imprenta en Murcia.

\section{New documents on 18th century murcia typography}

\begin{abstract}
In June 1788 the printers Manuel Muñiz and Antonio de Santa María set up to create a joint printing press reported as the first one to be established in Murcia city. One month later, they registered it at Francisco Bocio's record office in order to formalize this partnership and establish the conditions for its management. The information from this documentation together with other literature about the story of the Plano de San Francisco street printing shop cast light on a 18th century murcian press history section.
\end{abstract}

Keywords: 18th century printing press; Murcia printing shops; Printing company; Murcia printers.

\section{INTRODUCCIÓN}

Para los interesados en la tipografía murciana del siglo XVIII los nombres de José y Felipe Díaz Cayuelas, Antonio de Santa María o Manuel Muñiz constituyen referencias perfectamente reconocibles; sus talleres, la ubicación geográfica dentro de la ciudad, la naturaleza de sus producciones o los años aproximados de ejercicio profesional son datos conocidos por encontrarse reiteradamente citados en la literatura sobre el tema. Sin embargo, la localización de nuevas informaciones permite hoy tener un conocimiento más exacto de sus relaciones profesionales y 
personales, del devenir de sus talleres a lo largo de la centuria y de otros aspectos de índole sociológica hasta ahora ignorados.

A través del contenido de varias escrituras públicas suscritas por los impresores, vamos a reconstruir un tramo de la historia de la imprenta murciana del Setecientos. Partiremos de los años conocidos de la oficina de Díaz Cayuelas para pasar, seguidamente, a describir la situación material del taller después de su cierre temporal hacia 1774, las condiciones de su reapertura mediante el arriendo a un desconocido tipógrafo a inicios de los años 80 y la posterior modificación del contrato con la entrada en escena del impresor Santa María. Finalmente, abordaremos la formación en 1788 de la única imprenta mancomunada de que tenemos constancia, las circunstancias personales y laborales de los socios y el breve recorrido de la misma.

\section{EL TALLER DE LOS DÍAZ CAYUELAS}

Durante los años 70 de la centuria ilustrada dejaba de funcionar uno de los talleres con mayor solera de la imprenta murciana, una oficina que había comenzado su andadura hacia 1711, año del primer impreso conocido estampado por José Díaz Cayuelas en el Plano de San Francisco ${ }^{1}$. Tras la muerte del fundador en 1738, el establecimiento seguiría abierto bajo la dirección de un sobrino del maestro que, con toda probabilidad, se habría formado al lado de su tío. A partir de entonces, el nombre de Felipe Díaz Cayuelas figuraría en los pies de imprenta de no pocos textos a lo largo de una treintena de años.

La familia Cayuelas había detentado tradicionalmente los títulos de Impresor de la Ciudad y del Santo Oficio, cargos que habían favorecido las necesarias relaciones sociales y los buenos contactos con las elites rectoras murcianas. A diferencia de otros impresores y libreros, los Cayuelas poseían un abundante patrimonio: las tierras en el campo y en la huerta, más las casas en los barrios de San Juan y San Antolín, que serían a lo largo de los años un respaldo económico para mantener activa la imprenta. Hay que tener en cuenta que las características del siempre menguado mercado local constituían un grave impedimento para la subsistencia de estos trabajadores manuales que con frecuencia se veían obligados, ante la carencia de trabajo impresor, a cerrar el negocio y buscar en otros reinos el ejercicio de su arte. Si durante la vida del fundador, que conseguiría ampliar el negocio en Orihuela, las dificultades económicas no parece que fueran agobiantes, dada la

${ }^{1}$ Historia de la alma, vida del hombre, finezas del mejor padre...: primera parte... por el $P$. Fr. Isidro de S. Miguel... de Religiosos Descalços de N.S.P.S. Francisco. En Murcia: por Joseph Diaz Cayuelas...: a costa de Juan Lopez..., 1711. 
cuantía de la herencia dejada a los suyos ${ }^{2}$, durante el segundo período tipográfico el sobrino hubo de afrontar situaciones críticas para mantener a su no menguada familia, gestionar un patrimonio cargado de censos y el conreo del negocio con el pago a los oficiales, renovación de utillaje y un largo etcétera. Las respuestas generales del Catastro de Ensenada recogen que, en 1756 con cerca de 50 años, casado y con 4 hijas, ingresaba por la imprenta 2.520 reales al año, dineros que sumaba a los bienes obtenidos a la muerte de su tío José ${ }^{3}$. Pero en 1761 al heredar su legítima paterna -parte de una casa en la calle Corredera, tierras en la huerta y el campo- declaraba deber dinero a sus hermanos y muy pronto los más de 17.000 reales que le habían correspondido no mejorarían sus problemas de liquidez. A pesar de haber hipotecado su propia vivienda, uno de sus cuñados, Juan Marín Penalba, lo había tenido que socorrer en repetidas ocasiones con préstamos que irían incrementando sus deudas hasta que en 1768 le vendía su casa de la calle de Las Pilicas en la parroquia de San Antolín ${ }^{4}$.

En 1772 la precariedad económica de Cayuelas bien pudo afectar al funcionamiento del taller. En ese tiempo dejaba de imprimir de manera exclusiva para el Ayuntamiento, institución a la que reclamaba de continuo los pagos correspondientes ${ }^{5}$. Será precisamente en este año cuando ante escribano público el maltrecho impresor declaraba que hacía unos años que el mencionado Juan Marín había puesto a su disposición una nueva fundición de letra traída de Madrid y los pertrechos procedentes de la imprenta de los Franciscanos, comprada por su cuñado en 1767 al cerrar aquella sus puertas. Ante la imposibilidad de hacer frente al pago de los 14.000 reales desembolsados por Marín, se veía obligado a entregarle la mitad del usufructo de las propiedades vinculadas por José Díaz Cayuelas en su testamento ${ }^{6}$.

El panorama que hemos descrito da idea clara de las dificultades económicas que el dueño del taller hubo de afrontar a lo largo de su vida profesional. La lectura de su propio testamento firmado dos días antes de su muerte, en mayo de 1776, nos habla de la situación de dependencia que seguía manteniendo con Marín, quien había pasado de cuñado a yerno al casar con Josefa, la hija mayor del impre-

${ }^{2}$ A.H.P. Murcia. Prot. 3825, ante José Ramos, 1738, f. 564-565 v. "Poder de José Díaz Cayuelas para testar a José Rubio, presbítero" y f. 904-917 v. "José Díaz Cayuela, vecino que fue de esta Ciudad, su Testamento".

${ }_{3}^{3}$ Murcia 1756 Según las Respuestas Generales del Catastro de Ensenada. Introducción de Guy Lemeunier. Madrid: Ediciones Tabapress, 1993, p. 167.

${ }^{4}$ A.H.P. Murcia. Prot. 3071, ante Jiménez Aranda, 1768, f. 227-329 v. "Juan Marín, venta real contra Felipe Díaz Cayuelas".

${ }^{5}$ En 1771/72 el tipógrafo Teruel comenzaba a poner sus prensas al servicio de los munícipes con la impresión de varias reales cédulas. En 1774 aparece ya como "impresor de la Ciudad".

${ }^{6}$ A.H.P. Murcia. Prot. 3075 ante Jiménez Aranda, 1772, f. 15 y ss. Una parte de dichas propiedades vinculadas eran más de un centenar de fanegas plantadas de oliveras, higueras y viñas, con tres cuerpos de casa, pozo y aljibe. Una buena muestra del rico patrimonio de la familia Cayuelas la podemos ver en: "Bienes de don Felipe Díaz Aguado" A.M. Murcia. Legajo 2901. 
sor ${ }^{7}$ Tal vez 1774 fuese el último año en que el impresor pudo mantener activas sus prensas, pues no hemos localizado ningún otro trabajo posterior a la Novena de el glorioso San Antonio de Padua fechada en ese año. Hasta aquí, por tanto, llegaría el segundo período tipográfico del taller del Plano de San Francisco. La oficina permanecería cerrada varios años, pero no de modo definitivo como ahora veremos.

\section{ARRENDAMIENTO Y UTILLAJE DE LA IMPRENTA}

El primer documento que informa sobre los "años perdidos" de la conocida imprenta es una escritura de arrendamiento de septiembre de 1783. En ella Antonio Navarro, un vecino de la ciudad, firmaba el arriendo de la antigua imprenta a Felipe Marín a quien su padre había dado poderes para efectuar el trato ${ }^{8}$. El apoderado en cuestión era fruto del matrimonio de Juan Marín con su primera mujer, María Díaz Cayuelas y, por tanto, sobrino del tipógrafo, un grado de parentesco que se había hecho más intenso al casar en 1770 con su prima Ginesa, otra de las hijas del impresor. Así pues, los matrimonios de los Marín, padre e hijo, habían acabado convirtiéndolos en yernos de Cayuelas y receptores finales del patrimonio de la familia en razón de dichos lazos familiares pero, también, de los préstamos y de las deudas.

Según se declara en el concierto, la inactiva imprenta que había pasado a poder de Marín después de la ruina de Felipe Cayuelas, se encontraba instalada en un cuarto de la azotea de su propia vivienda en la Plazuela del Colegio de la Purísima. En dicho cuarto debía permanecer tras su puesta en funcionamiento aunque era preciso llevar a cabo algunas reparaciones en la azotea, arreglos que debían correr por cuenta del arrendatario. El contrato tendría una duración de 8 años y su coste se fijaba en 1.300 reales al año pagados de por mitad -650 en junio y otro tanto en Navidad-. La primera media paga debía abonarse el día de San Juan de 1786 y la segunda el día de Pascua del mismo año.

Junto a la explícita indicación de lugar, los años de validez de lo pactado y la cuantía del arriendo, como era habitual en este tipo de tratos, la descripción de los pertrechos que componían el bien arrendado nos ofrece la posibilidad de calibrar las características de aquella oficina en el momento de su clausura a inicios de los años 70. Veamos, pues, en qué consistía la afamada imprenta Cayuelas, la primera que hemos visto medianamente descrita en los protocolos murcianos. El listado es el siguiente:

${ }^{7}$ A.H.P. Murcia, Prot. 3079, ante Jiménez Aranda, 1776, f. 180-181v. "Don Phelipe Dias Cayuelas a la Parroquia de San Antolín, su testamento". Aunque el impresor deja como herederas a sus cuatro hijas: Josefa, María, Petronila y Ginesa, declaraba previamente que "ettenido diferentes cuenttas con el cittado Don Juan Marín, mi yerno, de las que en el día estamos solventes uno y otro..."

${ }^{8}$ A.H.P. Murcia. Prot. 3086, ante Jiménez de Aranda, 25 agosto 1783, f. 271-272 v. "Felipe Marín, arrendamiento contra Antonio Navarro". 
- 1 prensa para papel (satinar el papel o prensar las impresiones)

- 32 cajas y media completas para letra (cajas tipográficas)

- 31 pies de las dichas cajas (chibaletes)

- 38 galeras entre malas y buenas (tablas para ubicar las líneas de texto ya compuestas)

- 22 tablas para poner formas (rama o marco de la forma tipográfica)

- 5 cajones de conducir letra (para el transporte)

- 5 mesas y 3 bancos

- 4 frasquetas sueltas (bastidor con que se sujeta al tímpano de la prensa el pliego a imprimir)

- 2 ramas grandes y sus imposiciones corrientes (marco de la forma tipográfica)

- 340 láminas y figuras de todas clases de madera (estampas xilográficas y viñetas para cabeceras y remates, )

- 4 adornos de madera completos (para orlar portadas)

- 14 piezas sueltas de distintos géneros (?)

- 150 letras de madera (abecedarios de letras floridas)

- 1 tórculo (prensa para tirar láminas calcográficas)

- 4 tablas para miñetas (?)

- 6 tablas para mojar papel (antes de imprimir el pliego)

- 2 piedras para batir la tinta

- 2 prensas, una grande y otra pequeña

- 14 láminas de cobre (planchas calcográficas)

- 106 arrobas de letra (fundiciones o surtido de letras para imprimir)

Hasta aquí la somera descripción que, sin embargo, podría servir para valorar el tamaño aproximado de la oficina murciana y sus posibilidades en relación a otros talleres hispanos de la época. Antes de nada, convendría señalar que no se reseña ningún útil relacionado con la actividad ligatoria. Es posible, por tanto, que a diferencia de otras imprentas los Cayuelas no llevaran a cabo la encuadernación de sus impresiones y que aquellas saliesen siempre en rama para ser puestas en forma por los libreros.

Centrándonos en el utillaje declarado, si consideramos el número de prensas, una grande para libros y otra pequeña destinada a trabajos menudos, el taller podía considerarse de tipo medio dentro de las características propias de la tipografía española del Setecientos. Entre los madrileños reseñados por Larruga y Boneta sólo los de Delgado y Muñoz del Valle disponían de 2, si bien la mayoría de los talleres capitalinos llegaban a 4 , con una media entre 3 y 7 prensas 9 . Por su lado, las oficinas navarras bien equipadas contaban normalmente con 2 , frente a las más

${ }^{9}$ NIETO SÁNCHEZ, J.A. Artesanos y mercaderes: una historia social y económica de Madrid (1450-1850). Madrid: Taller de Historia Social; Editorial fundamentos, 2006, p. 408. 
modestas de la primera mitad del XVIII que sólo dispusieron de una ${ }^{10}$. Para Javier Burgos los talleres hispanos de tipo medio solían tener un máximo de 3, un número que se iría incrementando en la segunda mitad de la centuria. Si en Valencia el de Benito Monfort, el taller mejor dotado fuera de la Corte, llegaba hasta 6, en 1775 la barcelonesa $\mathrm{M}^{\mathrm{a}}$ Ángela Martí y la casa Piferrer disfrutaban de 3 y 4 prensas respectivamente ${ }^{11}$. Ambas oficinas catalanas, al igual que la de Cayuelas en Murcia, contaban también con 1 tórculo. La presencia de esta clase de prensa, el tórculo, en el listado resulta algo sorprendente ya que en opinión de Jaime Moll no era frecuente que los impresores españoles contasen con tal artilugio; ni siquiera los grandes de la Corte como Ibarra lo tenían y era práctica común recurrir a talleres especializados ${ }^{12}$. La necesidad de disponer de esta prensa de especiales características para el tirado de las planchas de metal vendría determinada, según J. Itúrbide, por la inexistencia de talleres especializados en la propia ciudad, circunstancia que afectaba a los talleres navarros y, desde luego, a los de Murcia ${ }^{13}$.

Otro elemento que hay que tener en cuenta son las cajas destinadas a disponer los tipos para la composición. Si volvemos a considerar los talleres pamploneses adecuadamente equipados, el total de cajas disponibles solía rondar la treintena, una "cantidad que posibilita la impresión de libros de gran volumen" ${ }^{\text {. }}$. Como vemos, la cifra no difiere de las señaladas para el taller murciano, pero lo que proporciona la verdadera medida es precisamente la cuantía de las fundiciones que debían contener dichas cajas tipográficas. En este punto, las arrobas de letras anotadas, 106, se encuentran por debajo de otros parámetros conocidos. Según los cálculos realizados por Itúrbide, una fundición de letra pesaba unas 30 arrobas, por lo que media docena de juegos de letrería en un taller navarro bien equipado suponían unas $180^{15}$; en 1775 las fundiciones de los Piferrer sumaban 318 arrobas, una cifra más elevada como correspondía a una oficina importante ${ }^{16}$. Así pues, por lo que a los juegos de letras se refiere, no parece que dispusiera Díaz Cayuelas de los recursos tipográficos necesarios para un taller de tamaño mediano.

En cuanto a las galeras y las ramas, el listado transcrito cita 38 galeras entre malas y buenas, 2 ramas grandes, más otras 22 tablas para poner o levantar formas, un número similar al utillaje de taller pamplonés del tipógrafo Pascual Ibáñez que contaba 32 galeras y 14 ramas en 1775. El más dinámico y encumbrado Domech

${ }^{10}$ ITÚRBIDE DÍAZ, J. Escribir e imprimir. El libro en el Reino de Navarra en el siglo XVIII. Pamplona: Gobierno de Navarra; Institución Príncipe de Viana, 2007, p. 305.

${ }^{11}$ BURGOS, F.X. y PEÑA DÍAZ, M. "Imprenta y negocio del libro en la Barcelona del siglo XVIII. La casa Piferrer". Manuscrits: Revista d'història moderna, 1987, 6, p. 199-200.

${ }^{12}$ MOLL ROQUETAS, J. "El taller de la imprenta". En: Historia de la edición y de la lectura en España 1472-1914. Madrid: Fundación Germán Sánchez Ruipérez, 2003, p. 36.

${ }_{14}^{13}$ ITÚRBIDE DÍAZ, J. Op cit., p. 305.

${ }^{14}$ Ib., p. 294

${ }^{15} \mathrm{Ib}$., p. 288

${ }^{16}$ BURGOS, F.X. y PEÑA DÍAZ, M. Op. cit., p. 200. 
tenía 48 galeras y 22 ramas; cosa bien distinta era el caso de la modesta oficina de Anchuela, también en Pamplona, que disponía tan sólo de 12 galeras y 8 ramas ${ }^{17}$.

Al examinar los útiles anotados llama poderosamente la atención la cantidad de láminas de madera, viñetas para cabeceras o remates y orlas, elementos que quedan recogidos en las 340 láminas y figuras de todas clases de madera, y los 4 adornos de madera completos; a todo esto hay que sumar el abundante stock de iniciales xilográficas -150 letras-. Tan desmedido utillaje en madera nos lleva a imaginar un taller perfectamente equipado, cosa bien alejada de la realidad. Este hecho lo hemos podido verificar a través del análisis de los productos salidos de sus prensas, unos impresos decorados en exceso en no pocas ocasiones, pero de poca o mediana calidad en su factura.

Si realizamos un balance de la producción desde esta perspectiva, lo primero que se observa es que los gestores de la imprenta no debían hacer grandes dispendios en proveerla de alfabetos floridos. El número de iniciales de nueva factura fue siempre reducido y nunca dispuso de letras calcográficas. Su principal fuente de suministro fueron las utilizadas por otros talleres murcianos y las no recicladas suelen ser imitaciones de inferior calidad (fig. 1). Un ejemplo de esto último lo encontramos en un bonito abecedario que reproduce el empleado por Jaime Mesnier desde 1704 (fig. 2). Entre las iniciales amortizadas y, por tanto, de coste más reducido, tenemos varios abecedarios procedentes del taller de Vicente Llofríu (1688-1711) que pasarán a la imprenta del Plano de San Francisco en su primera época (fig. 3). También acabarían en aquellas cajas las que habían pertenecido a la imprenta de los Franciscanos (1753-1766), lo mismo que el factotum que será ampliamente reproducido por Cayuelas (fig. 4). El deseo del fundador del taller por acaparar iniciales lo llevaría a engalanar sus impresos con letras procedentes de varias imprentas murcianas del XVII. De este modo, algunas de las más bellas letras floridas empleadas por Luis de Berós (1617-1635) pasarán a Fernández de Fuentes (1635-1650) y de este impresor al taller que nos ocupa (fig. 5). Es el mismo caso de la inicial A (fig. 6) que de Miguel Llorente (1655-1687) y a través de Llofríu, llegaría a Cayuelas; la citada inicial forma parte del ornato con que Miguel Llorente imprimió en 1672 las Insignias militares, la misma pieza empleada por Vicente Llofríu ${ }^{18}$ en 1701 y que vemos estampada casi 80 años después por Felipe Díaz Cayuelas ${ }^{19}$.

${ }_{18}^{17}$ ITÚRBIDE DÍAZ, J. Op. cit., p. 292.

${ }^{18}$ El Ezechias de la ley de gracia: oracion funebre panegyrica, en las reales exequias, que la... Ciudad de Murcia, consagró à... D. Carlos Segundo de Austria ... Rey de las Españas, el dia veinte y dos de Diziembre de 1700 en la Santa Iglesia Catedral ... En Murcia: por Vicente Llofriu, 1701.

${ }^{19}$ Exequiales honras... que a... Fr. Antonio Matheos... Prior Provincial de la Provincia de Andalucía, Orden de Predicadores: hizo su... Convento de Santo Domingo de Murcia y dixo el M. R. P. Fr. Joseph Funes . En Murcia: por Phelipe Diaz Cayuelas, 1748. 
Por lo que a las viñetas se refiere, observamos igualmente el empleo de tacos originales o de nueva factura (fig. 7), al mismo tiempo que detectamos también la presencia de otros procedentes del siglo anterior como el reproducido en la figura 8, un remate perteneciente al taller de Miguel Llorente en Murcia; el impresor lo estampó en 1683 en su Heraclito defendido de A. Vieira y muchos años más tarde lo vemos de nuevo reutilizado por Cayuelas ${ }^{20}$. Del mismo modo que hemos visto al referirnos a las iniciales, José Díaz se haría reproducir un remate idéntico al utilizado por Jaime Mesnier en impresiones oriolanas y murcianas ${ }^{21}$, pero de nuevo la calidad de la copia es notablemente inferior al modelo que imita (fig. 9). Caso similar es el que presenta la xilografía de la Inmaculada, un grabado que el impresor de origen francés poseía ya de su etapa en Orihuela y que tenemos documentada desde 1694 (fig. 10) ${ }^{22}$; como podemos apreciar, Díaz Cayuelas sólo lograría una mediocre imitación del taco de su colega (fig. 11).

En definitiva, la acumulación sistemática de todo tipo de ornatos en madera había convertido el taller en un almacén de xilografías, elementos decorativos que en más de una ocasión dejan traslucir el desgaste de sus muchos años y una estética barroca ya trasnochada en la segunda mitad de la centuria. La compra de materiales de segunda mano a precios reducidos, procedentes de imprentas ya amortizadas, explicaría también el exagerado número de cajas tipográficas, galeras y ramas, cantidades más en consonancia con una oficina de mayor envergadura. Por esta razón, la abundancia de determinados útiles contrasta con la escasez de fundiciones, circunstancia propia de un taller de tercera fila. Es evidente que la poca duración en buen estado de las letrerías procedentes de otras imprentas no podía solucionar la precariedad de las cajas de Cayuelas. La compra de nuevas fundiciones hubiera requerido una inversión importante, unos dineros con los que no se pudo contar durante el segundo período tipográfico. Posiblemente, la última fundición en condiciones fuera la comprada en Madrid por Juan Marín a finales de los 60 o comienzos de los 70. De ahí que en 1783, entre las condiciones del contrato de arrendamiento, se acordara posponer el inicio de los pagos casi tres años; durante esa moratoria el nuevo gestor debía invertir no pocos reales en la compra de nuevas fundiciones y otros enseres pues resultaba imposible poner en marcha el taller, dado el estado de degradación en que se encontraba. La lectura del concierto

${ }^{20}$ Constituciones de la Santa Provincia de Cartagena de la Regular Observancia de N. S. P. San Francisco. En Murcia: por Joseph Diaz Cayuelas, 1721.

${ }^{21}$ El animado Cielo de Maria, S. Joaquin... por el R. P. Iuan Baptista Leon, de la Compañia de Iesus. En Orihuela: por Jayme Mesnier..., en la Calle Mayor, 1700. Oracion panegyrica de los Dolores de la Virgen Maria Nuestra Señora, por la Cruz de Christo, con glorias aplaudidas predicada, por el... P. M. F. Manuel Garcia y Alarcon... En Murcia: por Jayme Mesnier... en la Calle de la Plateria, 1708.

${ }^{22}$ Clypeus defensionis sive exorcismi efficaces et terribiles experientia probati. Oriolae: typ. Iacobi Mesnier..., 1694. 
pone de manifiesto este hecho y el interés de las partes por establecer con toda claridad lo concerniente a la provisión de tipos y demás utillaje. Dice así el texto ${ }^{23}$ : - Que el primer año de este arrendamiento dicho Antonio Navarro no ha de pagar cosa alguna por razón de él, a causa de allarse dicha imprenta y sus efectos muy deteriorados.

- Es condición que el segundo año de este arrendamiento el importe de él, que es el de los dichos un mil y trescientos reales vellón, lo ha de imbertir todo él, como también si fuese necesario más, en renobar parte de la letra que tiene dicha imprenta (...)

- Que dicho Navarro ha de continuar los demás años renobando letra y también los demás peltrechos y enseres que recive de forma que todo baya en aumento y no a menos.

- Que finados dichos ocho años el zitado Antonio Navarro ha de entregar dicha imprenta y peltrechos que recive todo ello corriente.

- Que si finado dicho arrendamiento y entregada dicha imprenta y peltrechos, y si hubiese aumentado el zitado Navarro alguna letra más, a efectos de dicha facultad, ha de quedar todo a beneficio de este, pero si el zitado Felipe Marín quisiere quedarse con ello deberá abonar su importe por lo que otro diese por que en tal caso ha de ser preferido.

Hemos referido anteriormente que la imprenta se encontraba en la parte alta de la casa de los Marín, una situación poco favorable pero que no era excepcional ${ }^{24}$. En el caso de Pamplona, dos de cinco talleres estudiados ocupaban la parte alta de las viviendas a pesar de los inconvenientes que originaba el acarreo de materiales y la estabilidad del piso con el continuo trasiego de las prensas. Junto a estos aspectos negativos, la proximidad con las terrazas facilitaría el oreo y rápido secado de los pliegos una vez estampados ${ }^{25}$.

No creemos que esta ubicación, descrita en la fuente notarial, corresponda con la vivienda que ocupó el taller desde su fundación. Cierto es que ambas casas se encontraban en el Plano de San Francisco, enfrente del convento y del colegio franciscano de la Inmaculada, pero nos consta que la imprenta estuvo instalada con anterioridad en unas casas del Ayuntamiento, locales que la Corporación, como era de rigor, proporcionaba al impresor de la Ciudad que era Cayuelas. Por el contrario, la casa principal referida en la escritura de arriendo, aunque pagaba un censo perpetuo al Ayuntamiento desde 1731, había sido construida desde sus cimientos por el pri-

${ }^{23}$ A.H.P. Murcia. Prot. 3086, ante Jiménez de Aranda, 25 agosto 1783. "Felipe Marín, arrendamiento contra Antonio Navarro", f. 271 v.

${ }^{24} \mathrm{Ib}$., "Que dicha imprenta ha de permanecer dichos ocho años en el quarto azotea de la casa principal propia de dicho Marín sita en la Plazuela de la Colexio de la Purísima Concepción".

${ }^{25}$ ITÚRBIDE DÍAZ, J. Op. cit., p. 260-261. 
mer Cayuelas sobre unas arruinadas casas municipales ${ }^{26}$. Esta vivienda, que lindaba por levante con el Plano de San Francisco, acabaría en manos de Marín como ocurriría con la mayor parte del patrimonio heredado por el impresor.

Pues bien, cuando Felipe Díaz Cayuelas en 1772 dejó de trabajar para los munícipes y pasó a depender de su cuñado a causa de las deudas, la imprenta que ya no era de su propiedad debió de ser trasladada al cuarto de la azotea de la casa principal del dueño efectivo de aquellos abundantes, pero deteriorados aparejos del arte impresor. También sabemos que el descapitalizado Cayuelas trabajó poco tiempo en el nuevo local, unos dos años, manejando la imprenta y cobrando los dineros que producía como si todavía le perteneciese. Naturalmente en su nueva situación no podía venderla, trocarla, ni ponerla como garantía de sus continuos impagos ${ }^{27}$.

\section{MODIFICACIÓN DEL CONTRATO}

La puesta en marcha de las prensas después de tantos años de inactividad, dentro ya del tercero y último periodo tipográfico, debemos situarla en 1784. De ese año conocemos dos impresos de contenido diverso, aunque sólo en uno de ellos se anota el nombre de Antonio Navarro en su portada. Se trata de un poema panegírico en latín salido de la pluma del franciscano Pedro Martín Stargia, maestro de latinidad, poesía y elocuencia en el Colegio de la Inmaculada, compuesto con ocasión de la muerte del Obispo Rubín de Celis en $1784^{28}$. El segundo impreso, fechado en el mismo año, aporta un nuevo nombre al frente del taller del Plano de San Francisco, Antonio Santa María, el verdadero maestro impresor que llevaba de hecho el conreo del negocio ${ }^{29}$. La aclaración a tan extraña circunstancia que contravenía los términos de lo firmado nos la proporciona una nueva escritura de declaración y cesión suscrita por Antonio Navarro en agosto de $1786^{30}$. En ella el arrendatario afirmaba que ante la imposibilidad de seguir con el encargo suscrito

${ }^{26}$ A.H.P. Murcia. Prot. 3273, ante López Baeza, 1731, f. 49-54 v. "Los muy Ilustres Sres. del Ayuntamiento de esta Ciudad, dación de zenso perpetuo contra José Díaz Cayuelas, vecino de ella".

${ }_{27}$ A.H.P. Murcia. Prot. 3075 ante Jiménez Aranda, 1772, f. 15 y ss. La escritura de cesión de la imprenta se encuentra trascrita en: GARCÍA CUADRADO, A. "Los Royo en la Murcia del siglo XVIII: apuntes sobre librería y conflictos entre libreros". Carthaginensia, XXV, 2009, 48, p. 433-434.

${ }^{28}$ Panegyricum poema: in quo quaedam praeclara describuntur illmi D. D. Emmanuelis Rubin de Zelis... elucubratum a P. Fr. Petro Martinio Stargia... Frat. Min. de Observ. S. P. N. Franc. ... Ann. Domini MDCCLXXXIV. Murciae: apud Antonium Navarro, in Platea S. P. Francisci, [s.a.].

${ }^{29}$ Instruccion moral, político-militar que el Coronel Don Felis de Copons... dexó à su hijo, don Manuel de Copons... En Murcia: en casa de Antonio de Santa Maria, 1784.

${ }^{30}$ A.H.P. Murcia. Prot. 3089, ante Jiménez Aranda, año 1786, f. 131-132 v. "Felipe Marín y Antonio Navarro, escritura de declaración y zesión a favor de Antonio de Santa María". 
tres años atrás, cedía a Antonio Santa María, su sobrino y maestro impresor, el arriendo con el beneplácito de Felipe Marín. En nuestra opinión, esta cesión de los derechos del arriendo "oficializada" a través de la citada escritura estuvo motivada por la situación irregular en que se estaba utilizando la imprenta. Tal hecho explicaría el nombramiento de procuradores por parte de Marín, en noviembre de 1785, con vistas a entablar pleito con Navarro para hacer valer las condiciones del contrato $^{31}$.

Antes de continuar desgranando los datos hasta ahora desconocidos, deberíamos contestar a dos cuestiones. En primer lugar, ¿quién era Antonio Navarro? Con las escasas informaciones de que disponemos por ahora no podemos afirmar que hubiese ejercido de impresor en algún momento. Sí es posible, sin embargo, que estuviese emparentado con Francisco Navarro, un librero de la ciudad que había trabajado durante la primera mitad de la centuria en el barrio de San Pedro muy cerca del taller de los Cayuelas ${ }^{32}$. Quizás por este motivo Navarro se encontrara familiarizado e interesado en las artes del libro y decidiese irrumpir en el ámbito tipográfico en calidad de "socio capitalista". En cuanto al maestro impresor Antonio de Santa María y Barrio, mano derecha del arrendatario, sabemos que era natural de la ciudad de Burgos y parece que había trabajado en Orihuela un tiempo antes de su llegada a Murcia. De 1779 conocemos una gramática latina que bajo el título de Instruccion breve para los gramaticos en todas clases fue impresa por Santa María con destino a los alumnos del Patriarcal Colegio de Predicadores de Orihuela. Poco después abandonaba el reino vecino y pasaba a residir en Murcia donde casaba con la murciana Manuela Navarro, sobrina del gestor del taller. El enlace de la pareja tuvo lugar en la parroquial de San Antolín en diciembre de 1786, unos meses después de haberse producido la cesión del arriendo por parte del tío político del impresor ${ }^{33}$.

En efecto, el propio Santa María en compañía de su esposa Manuela declaraba ante notario en septiembre de 1789 que "contrajeron matrimonio (...) y desde que

${ }^{31}$ A.H.P. Murcia. Prot. 3088, ante Jiménez Aranda, año 1785, f. 430.

${ }^{32}$ A.H.P. Murcia. Prot. 3272, ante López Baeza, 1728, f.6 "La ciudad de Murcia arrendamiento vitalicio contra Francisco Navarro" La casa arrendada estaba situada cerca del Colegio de la Purísima, la $\mathrm{n}^{\circ}$ 12, parroquia de San Pedro. A partir de 1735 Navarro compartiría el monopolio de impresión para Murcia de una serie de libros doctrinales a través de los privilegios cedidos por los libreros de San Gerónimo de Madrid. En 1743 el padrón parroquial recoge que era maestro librero, estaba casado, tenía 64 años y se encontraba enfermo. De los hijos habidos en su matrimonio con Ana Ramírez de Arellano sólo le habían sobrevivido, entre los varones, Bernardino, de 21 años, oficial en el registro de Gregorio Martínez, y el más pequeño, José, de 14 años.

${ }^{33}$ El origen burgalés del impresor aparece recogido tanto en la partida de matrimonio (1786) como en la de bautismo de su hijo José. Sus padres, Ángel Santa María y Antonia del Barrio eran también naturales de Burgos. Sus suegros, José Navarro y Buenaventura Martínez procedían de Elche, en el Obispado de Orihuela. Tanto unos como otros eran vecinos de Murcia en 1788. Libros de Bautismo de S. Antolín, año de 1788. 
tubo efecto hasta de presente permanecieron y estuvieron en las casas y compañía de José Navarro y Ventura Martínez de esta ciudad, padres y suegros respectivos..." Seguía exponiendo el impresor que "al tiempo de separar su domicilio recivió diferentes vienes prometiendo otorgar a su favor [el de su esposa] el competente resguardo y carta dotal haciendo descripción formal" de ellos, tanto de los propios como de los recibidos por las legítimas y dote de su mujer. La relación de los aportados al matrimonio por el impresor -un buen surtido de ropas de vestir, unas láminas de cobre de tarjetas y 16 láminas de madera de varias clases- sumaban poco más de 1.300 reales, una cifra inferior al valor de los llevados por Manuela que fueron tasados en cerca de 4.000 reales de vellón ${ }^{34}$. El traslado de vivienda del joven matrimonio al que alude la escritura debió de coincidir con la llegada del primer hijo -el futuro impresor José Santamaría y Navarro- en enero de 1788. Según consta en su partida bautismal José fue apadrinado por el librero Juan Polo Ruiz y bautizado en San Antolín, parroquia de la que eran feligreses sus padres como lo eran todos los vecinos del Plano de San Francisco.

La asunción por parte del burgalés del contrato de arrendamiento le obligaba a no dejar la imprenta hasta septiembre de 1791 "pena de pagar su renta de vacío" y a guardar y cumplir las condiciones establecidas en su momento. Es posible que el incumplimiento de alguna de ellas fuera la causa de problemas y pleitos con el nombramiento de procuradores en octubre de 1786 por parte del impresor ${ }^{35}$. Lo cierto es que Antonio siguió trabajando en los años sucesivos poniendo en el mercado un pequeño número de impresos de contenido religioso, el Compendio matemático de Bañón y otros textos de carácter educativos, más unas fiestas ciudadanas con motivo del cumpleaños regio. La búsqueda en el Catálogo Colectivo del Patrimonio Bibliográfico Español nos ha proporcionado tan sólo 10 títulos con data entre 1785 a 1788, año en el que Santa María acudiría al registro notarial.

\section{DOS MAESTROS IMPRESORES Y UNA COMPAÑÍA}

En opinión de R. Franch, la constitución en España de sociedades mercantiles, asumidas también por las gentes del libro, adoptará durante la segunda mitad del siglo XVIII unas peculiares características con la aparición de las sociedades por acciones. Es el tipo de asociación formada por la madrileña Compañía de Impresores y Libreros del Reino (1763), cuyos antecedentes podemos encontrar en la de Mercaderes de libros de la Corte, y la más temprana de Impresores y Libreros de Valencia de 1759. Sin embargo, frente a estas modernas sociedades, propias de la mentalidad mercantilista de la época, la forma más habitual en la que los comer-

\footnotetext{
${ }^{34}$ A.H.P. Murcia. Prot. 2610, ante Calahorra, año 1789, f. 235-238 v. "Antonio Santa María, Escritura de desereción de sus bienes y de los dotales a favor de Manuela Navarro, su mujer".

${ }^{35}$ A.H.P. Murcia. Prot. 3089, ante Jiménez Aranda, 1786, f. 159. "Antonio Santa María, poder general a Manuel Ibarra y Consortes"
} 
ciantes solían unir sus capitales y esfuerzo personal era la formación de compañías generales o colectivas en las que los socios se obligaban a crear un fondo patrimonial común para colaborar en la actividad a desempeñar con objeto de repartirse los beneficios ${ }^{36}$.

Por lo que a Murcia se refiere, la creación de sociedades por parte de impresores y libreros en la segunda mitad del siglo fueron prácticamente inexistentes y cuando las hubo, lo fueron de tipo colectivo y de escasa duración ${ }^{37}$. De hecho, hasta ahora sólo conocíamos la formada en 1794 por el mercader de libros Francisco Benedicto con uno de sus nietos, noticia que daremos a conocer en un próximo trabajo ${ }^{38}$. Pero a comienzos del verano de 1788 Antonio de Santa María y un todavía desconocido maestro impresor de la ciudad, Manuel Muñiz, decidían aunar esfuerzos y caudales para poner en marcha una oficina en la céntrica y concurrida calle de la Trapería. Pocos días más tarde pasaban por el notario para dejar constancia de la constituía compañía "para maior fomentto de este Arte, beneficio público y privado en que aquel se interesa el Real servicio y estado de la Patria" $" 39$.

Según el texto del concierto, ambos maestros habían invertido no pocos reales en la compra de los pertrechos sin los cuales no podría funcionar una imprenta en condiciones; entre ellos se citan prensas y unas letras que habían hecho traer de la ciudad de Barcelona. El nuevo establecimiento contaba, por tanto, con más de una prensa y sus fundiciones no procedían de la Corte, del obrador de Espinosa de los Monteros, como solía ser habitual entre los tipógrafos murcianos, sino de Barcelona, ciudad donde se podían adquirir por esos años las que fabricaba el convento carmelita de San José e $^{40}$.

${ }^{36}$ FRANCH R. Y MESTRE, A. "La compañía de Impresores y Libreros de Valencia: finanzas y cultura en el siglo XVIII. Revista de Historia Moderna. Anales de la Universidad de Alicante, 1984, 4, p. 25-26. GARCÍA CUADRADO, A. "La Compañía de Mercaderes de la Corte a mediados del siglo XVIII". Anales de Documentación, 2001, 4, p. 95-126.

${ }^{37}$ De carácter modesto y efímero califica Itúrbide a las compañías de libreros e impresores navarros del siglo XVIII, pero su aparición fue temprana, en 1745. Op. cit., p. 189. Entre los libreros de Murcia tenemos documentada la constituida en 1735 por Juan Royo y Juan Polo para imprimir y vender en el Reino los libros doctrinales procedentes de la cesión del privilegio obtenida de los libreros de San Gerónimo. GARCÍA CUADRADO, A. "Cesión del privilegio de impresión de libros doctrinales para el Reino de Murcia". Tejuelo, Revista de AnabadMurcia, 2009, 9, p. 39-42.

${ }_{39}^{38}$ A.H.P. Murcia. Prot. 2581, ante Gregorio Buendía, 1794, f. 10-12 v.

${ }^{39}$ A.H.P. Murcia. Prot. 2538, ante Francisco Bocio y Belda, 1788, f. 194-197 v.

40 Según A. Corbeto, al dejar el gran fundidor catalán Pradell Barcelona para trabajar en Madrid, la fundición de los carmelitas de Barcelona pasaría a ser prácticamente el único centro suministrador de letra de imprenta en Cataluña. CORBETO, A. Eudald Pradell y la fundición del convento de San José. [en línea] [consulta: 20 abril 2011] [disponible en: www.unostiposduros.com.] [Texto presentado en el Primer Congreso Internacional de Tipografía, Valencia 2004] 
Junto a estas aclaraciones se daba noticia puntual de la situación en que se encontraba Santa María y que nosotros ya conocemos ${ }^{41}$, pero al conformarse en sociedad, competía a ambos socios hacer frente al pago anual del arriendo de la imprenta Cayuelas desde esa fecha, un asunto de gran interés para el impresor. Aunque la inversión realizada se había hecho por mitad, los útiles que Santa María tenía comprados para acondicionar el antiguo taller pasarían, finalizado el arriendo, a la imprenta mancomunada; por esta razón la mayor inversión realizada por Antonio obligaría a Muñiz a igualar dicha cantidad. Los pertrechos que Santa María pensaba incorporar al patrimonio común llegado el momento no eran, sin embargo, abundantes ya que se reducían a unas láminas de latón, otras de maderas, letras de dos puntos ${ }^{42}$, diferentes orlas y adornos de metal.

Correspondía a Muñiz la dirección del taller que se encontraba instalado en "sus casas" de la Trapería -unos locales probablemente arrendados-, la toma de decisiones, los ajustes, pagos y demás actividades que en ella se realizasen, siempre con conocimiento del otro socio. Y para el buen gobierno de la naciente sociedad, los útiles comprados debían ser inventariados y los ingresos producidos por el trabajo impresor de ambos, así como los libros de cuenta y razón con las anotaciones mensuales correspondientes debían quedar depositados en un arca de dos llaves sita en el propio local de la imprenta.

Era intención de los asociados que la compañía fuera permanente por lo que fue constituida a perpetuidad y para siempre. De ahí que las condiciones suscritas estableciesen con claridad y minuciosidad la solución que se adoptaría en el caso de producirse posibles eventualidades e incluso la muerte de alguno de ellos. Así, si uno de los socios enfermase o quedase inhabilitado para trabajar, tal circunstancia no provocaría la disolución de la misma. Por el contrario, el afectado pondría un oficial que realizase sus funciones y a quien habría de pagar con sus correspondientes ingresos. Se podría nombrar, si fuese necesario, un gestor externo para el manejo y comprobación del negocio con objeto de preservar los intereses de su representado. Ahora bien, ante la dificultad que entrañaba encontrar oficiales de imprenta capaces de desempeñar con corrección sus tareas, dejaban abierta la posibilidad de cargar el trabajo del enfermo sobre su compañero. En tal caso las ganancias se repartirían en tres partes, una para el impedido y dos para el impresor que hubiera sumido la carga. Esta previsión obraría, también, siempre que uno de los socios se ausentase por los más diversos motivos que pudieran producirse.

${ }^{41}$ A.H.P. Murcia. Prot. 2538, ante Francisco Bocio y Belda, 1788, f. 194: “...tiene a su cargo por arrendamiento de Juan y Felipe Marín una imprenta situada en el Plano que llaman de san Francisco intitulada Felipe Díaz Cayuela, en precio de un mil y trescientos reales años de cuio arrendamiento le restan tres..."

${ }_{42}$ Mayúscula que se suele usar en los carteles, titulares y principios de capítulo, que suele aparecer fundida en dos líneas del cuerpo de su grado. 
Pero además, en aras de favorecer la permanencia de la compañía ante el fallecimiento de alguno, la viuda y los hijos podrían, si era su deseo, continuar en la misma nombrando un oficial con la suficiente preparación para afrontar la actividad correspondiente al difunto. Si no pudiesen encontrarlo, el socio que quedara asumiría la totalidad de las tareas; naturalmente, los ingresos se dividirían en tres, dos partes irían destinadas al impresor y un tercio para la viuda e hijos. Con las utilidades que se produjesen podría alimentarse la familia del fallecido y, naturalmente, preservar el capital invertido. Se planteaba también la posibilidad de abandonar la compañía. De producirse esta situación, el socio superviviente se vería obligado a disolver el negocio devolviendo el capital correspondiente en tres pagas iguales cada seis meses a partir del día en que decidiesen su disolución. Finalmente, se especificaba que "si por casualidad, necesidad o urgencia de la viuda" e hijos quisieran percibir diariamente las ganancias que se produjesen, habría que recurrir a dos expertos para que determinasen o fijasen la cantidad, al tiempo que el socio quedaba obligado a entregarla.

La minuciosidad en la descripción de la casuística contemplada en las cuatro últimas cláusulas del concierto, creemos que se encontraba bien justificada. Hacía tan sólo unos meses que Santa María había tenido su primer hijo y, por tanto, parecía obligado pensar en el futuro de su familia y en su subsistencia en caso de enfermedad o fallecimiento del cabeza de familia. Una situación muy semejante era la del otro asociado, el impresor Manuel Muñiz y Gutiérrez, que según el padrón de Santa Catalina de 1786 se encontraba ya avecindado en Murcia en ese tiempo. Natural de la villa de Maraña en las montañas leonesas, había casado dos años atrás (julio 1784) con la murciana Magdalena Casajuz y en opinión de Candel Crespo habría trabajado en el taller de los Teruel en la cercana calle de la Lencería $^{43}$. El matrimonio tuvo su primer vástago en mayo de 1785 , un niño que moría a los dos años; pero en febrero de 1788 el impresor Juan Vicente Teruel apadrinaba, como ya hiciera con el primero, al segundo de los hijos de la pareja, el fututo presbítero e impresor don Luis Muñiz y Casajuz. Del mismo modo que ocurría con su socio, el incremento de la familia pudo ser determinante en la apertura de la oficina mancomunada, un medio de mejorar profesionalmente y asegurar para el futuro la supervivencia de los suyos.

\section{EL TALLER DE LA TRAPERÍA}

Es evidente que la asociación establecida afectaba al trabajo de las dos imprentas, aunque la base de la nueva compañía se encontraba en la apertura de la oficina tipográfica en común. Llegados a este punto, convendría hacer un inciso y pregun-

${ }^{43}$ Algunos datos sobre el impresor Manuel Muñiz Gutiérrez los recoge CANDEL CRESPO, F. "Don Luis Muñiz y Casajuz (1788-1860), sacerdote y periodista murciano". Anales de Historia Contemporánea. Universidad de Murcia, 1983, 2, p. 63-80. 
tarnos si ambos socios contaban en ese momento con un taller ya existente o, por el contrario, partían de cero. Aunque la escritura de concierto no lo indica explícitamente, los impresores asociados debían tener ya a su disposición el taller de Manuel Muñiz quien, según creemos, había dejado de ser asalariado y disponía de su propia oficina. La confirmación de esta suposición nos la proporciona el citado vecindario de Santa Catalina de 1786; en el largo listado de nombres el impresor Muñiz figura entre los pudientes, una condición que vemos asignada a otros impresores y libreros de su entorno, gentes que contaban con un negocio propio, mientras que Juan Vicente Teruel, el gestor de la imprenta del mismo nombre pero no su propietario, aparece como jornalero entre los vecinos de la parroquial de San Pedro ${ }^{44}$ ¿Cómo explicar este hecho? En nuestra opinión, el dato sólo cobra sentido si el impresor Muñiz hubiera pasado de asalariado a propietario de un taller antes de producirse la asociación con Santa María, un hecho que podemos intuir o leer entre líneas en la exposición de algunas cláusulas del concierto antes expuesto ${ }^{45}$. Estaríamos, por tanto, ante una manera de aliviar o compartir la inversión ya realizada por el primero, al tiempo que Santa María se convertía de ese modo en copropietario mejorando su condición de arrendado.

Sea como fuere, el primer problema a la hora de montar un taller tipográfico era su financiación, disponer de un capital, mayor o menor según el tamaño que se quisiera dar al establecimiento. Los dineros que se necesitaban -escribe Moll Roqueta- solían proceder de los ahorros del impresor, de la venta de alguna propiedad, de la dote de la mujer o de un crédito ${ }^{46}$. En el caso de Santa María sabemos que los bienes personales y la dote de su mujer no sumaban los reales precisos para financiar el proyecto y fue necesario encontrar un capitalista que adelantase el dinero. El impresor acudió a José Navarro, su suegro, quien le haría entrega de 8.000 reales de vellón. Una parte del crédito, 5.000 reales, iban destinados a la compra de fundiciones, cajas, prensas y otros utensilios propios del oficio; los 3.000 restantes se reservaban para la compra de papel, el gasto de las impresiones y demás conreos de toda oficina tipográfica. En el mismo acto notarial Santa María se comprometía a devolverlos en 1792. Los primeros 4.000 reales lo serían en junio y el resto en los años sucesivos de mil en mil hasta liquidar la totalidad de la deuda $^{47}$.

${ }^{44}$ A.M. Murcia. Legajo 1060. "Padrones de 1786". Que Juan Vicente Teruel figure como jornalero está perfectamente justificado. Aunque con el paso del tiempo acabaría siendo dueño de la imprenta de la Lencería, por entonces el establecimiento era todavía propiedad de la Viuda de Felipe Teruel, Antonia Ramírez, tía política de Juan Vicente.

${ }^{45}$ No hemos podido localizar impresos estampados con seguridad durante esa etapa primera del taller de Muñiz. Existen, sin embargo, un número significativo de impresos en cuyos pies de imprenta sólo consta el nombre del impresor, pero carecen de fecha de publicación. De lo contrario, dispondríamos de un dato incuestionable sobre lo dicho.

${ }_{46}^{46}$ MOLL ROQUETAS, J. Op. cit., p. 31.

${ }^{47}$ A.H.P. Murcia. Prot. 2610, ante Calahorra, 1789, f. 239. "Josef Navarro, vecino de esta ciudad, obligación contra Antonio Santa María”. 
Por lo que respecta a Manuel Muñiz, suponemos que también hubo de seguir la vía crediticia pues, aunque su padre había gozado de estado noble y él mismo, según declara en su testamento, heredaría bienes raíces en el leonés valle de Burón por vía materna, no creemos que gozara en ese tiempo de una economía florecien$\mathrm{te}^{48}$. En 1784 al contraer matrimonio con Magdalena, no pudo ofrecer otra cosa que las ropas de su uso, mientras que la novia aportó algunos bienes muebles, ropas y otros efectos heredados a la muerte de sus padres cuyo valor ascendía a 2.361 reales $^{49}$. Es evidente que el patrimonio declarado no podía cubrir el capital invertido, cuya totalidad bien pudo ascender a 16.000 reales, 8.000 por socio, un dinero prestado que habría que devolver a la vuelta de unos años.

Una vez constituida formalmente la sociedad, comenzaron a aparecer los primeros impresos procedentes de la oficina común. Naturalmente, Santa María continuaba con sus trabajos en el taller de San Antolín, al tiempo que los nombres de ambos socios figuraban de manera conjunta en los pies de imprenta de los textos estampados en la Trapería. Hay que advertir, sin embargo, que la suma de la producción entre ambos talleres nunca sería abundante, una cantidad exigua para la viabilidad de la compañía. Desde nuestro punto de vista, el futuro de la misma fue incierto desde su nacimiento por las características del mercado local en el que se desenvolvía. La débil demanda de impresos de calado, fuera de las menudencias literarias y las novenas, junto a una escasa clientela cubierta por las oficinas existentes -la de Benedicto en la calle Platería y la de Teruel, la más activa a lo largo de la segunda mitad del siglo- impedirían el despegue de la nueva imprenta. Por esta razón, los testimonios que conocemos del trabajo realizado por los asociados son tan limitados, aunque como es natural no podemos computar los impresos menores que solían permitir la subsistencia. Lo cierto es que no hemos encontrado impresos más allá de 1791, año que marca no sólo el término del arriendo de la imprenta Cayuelas, sino también el inicio del fin de la propia compañía.

\section{FINAL DE LA COMPAÑÍA}

En septiembre de 1790 la situación era ya muy preocupante lo que llevaría a Muñiz a formalizar el recibo de los bienes aportados por su esposa al matrimonio. El impresor declaraba ante notario que le había sido imposible hacer esta diligencia con anterioridad por sus muchas ocupaciones, pero tras la descripción y valoración de los mismos, añadía que renunciaba a la ley que le permitía retener para sí

${ }^{48}$ En marzo de 1784, unos meses antes de de contraer matrimonio, otorgaba poderes a su madre Antonia Gutiérrez, casada en segundas nupcias y residente en el Val de Burón (León) para que se practicase información de identidad y limpieza de sangre de su familia, padres y abuelos por ambas líneas. A.H.P. Murcia. Prot. 2650, ante Antonio de Canovas Hilario, f. 53.

${ }^{49}$ Testamento de Manuel Muñiz y Gutiérrez. A.H.P. Murcia. Prot. 4733, ante Moya y Quiñones, 1804 , f. 457-460 v. 
la dote y se comprometía a no hipotecar, ni obligar dichos bienes a sus deudas ${ }^{50}$. La suscripción de este documento debemos ponerla en relación con los problemas económicos y judiciales que aquejaban a los socios. Es necesario tener presente que en este tipo de asociación sus integrantes se hacían responsables solidaria e ilimitadamente con la totalidad de sus bienes frente a los acreedores, de ahí la necesidad de tratar de conservar por este procedimiento el menguado patrimonio de la familia ${ }^{51}$.

Efectivamente, Muñiz veía peligrar sus bienes porque su colega, que había sido padre de nuevo con el nacimiento de Florentina en marzo de 1791, hacía ya un tiempo que no podía hacer efectivos los pagos del arriendo a Marín, una obligación que correspondía ahora a los dos socios. Como resultado de estos impagos, Felipe Marín había iniciado las oportunas acciones judiciales en 1790, unos pleitos cuyas nefastas consecuencias recaerían en ambos impresores. Afortunadamente, en julio del año siguiente, "considerando ambos [Santa María y Marín] que de continuar los procedimientos judiciales (...) se les ha[bía] de seguir muchos perjuicios y quebrantos, así en sus personas como en sus bienes por las inquietudes que de suyo traen los pleitos, y a más de ello, inteligenciadas algunas personas de autoridad del estado de las cosas y del en que se halla[ban] los otorgantes, ha[bían] hecho los oficios posibles para tranquilizarlos y que cada uno quede[se] en el estado que corresponde..." El acuerdo alcanzado entre las partes se establecía en los siguientes términos ${ }^{52}$ :

- A partir de ese momento Marín tendría a su disposición la imprenta y todos sus aparejos. Ya se había hecho cargo de los útiles una vez reconocidos y se encontraba conforme con lo entregado por el impresor.

- El arrendatario quedaba libre del compromiso aunque faltaran dos meses para cumplir la fecha efectiva de terminación del mismo.

- Por el importe de los arrendamientos vencidos y no liquidados, Marín se conformaba con la cantidad de 1.000 reales que le serían pagados por el burgalés en dos plazos, 500 por todo el mes de abril de 1792 y la otra mitad al año siguiente.

De esta forma terminaba el problemático y accidentado arriendo de la imprenta de Cayuelas y concluía su último periodo tipográfico, ocho años en que sus prensas no alcanzaron el ritmo de producción que las había caracterizado en otras épocas. Ni que decir tiene que si la finalización del compromiso con Felipe Marín

${ }^{50}$ A.H.P. Murcia. Prot. 2368, ante Juan Mateo Atienza, 1790, t. II. f. 724-725 v. "María Magdalena Casajuz, recibo de dote contra Manuel Muñiz".

${ }^{51}$ FRANCH, R. y MESTRE, A. Op. cit., p. 31.

52 A.H.P. Murcia. Prot. 3150, ante Jiménez Pérez Rojo, 1791, f. 177-178 v. "Felipe Marín y Antonio Santa María, escritura de convenio y obligación”. 
había eliminado los problemas judiciales, los económicos continuaban siendo acuciantes. Por esta razón, el 17 de junio de 1792, los dos maestros acudían de nuevo ante notario para dejar constancia de la clausura de la compañía. El texto de la escritura de convenio y obligación informa del fin de la empresa y de otras varias cuestiones, a saber: ${ }^{53}$

- Que la separación de los socios se producía de mutuo acuerdo y por razones fundadas.

- Que en esa fecha Antonio de Santa María ya no se encontraba en Murcia. Tras abandonar la vivienda del Plano de San Francisco e instalarse como feligrés de Santa María, parroquia donde sería bautizada su hija, permaneció pocos meses al lado de Muñiz. Ante la falta de trabajo y los problemas económicos retornaba a Orihuela donde continuó ejerciendo como impresor. Por tanto, la clausura de la compañía parece que se había producido de hecho antes de la firma de la escritura de disolución.

- Que los impresores se encontraban endeudados con don Juan Capelo, un comerciante de la ciudad, que había afrontado las pérdidas de la compañía. Sobre este comerciante sólo conocemos su participación en calidad de suscriptor en los Triunfos de la verdadera religión, un impreso estampado por Muñiz en 1792.

- Que los dos habían liquidado cuentas quedando Muñiz debiendo a Santa María 850 reales que tendría que abonar en 1793. Una nota en al margen izquierdo de la escritura da fe de que la deuda fue cancelada en la fecha prevista.

- Que el convenio escriturado obligaba también a Manuel Muñiz a afrontar el pago de los últimos 500 reales que Santa María tenía que abonar a Marín al año siguiente.

- Que los préstamos que figuraban en el libro de cuenta y razón del comerciante Capelo serían devueltos en su totalidad por el mismo Muñiz.

Todas estas obligaciones asumidas por el impresor ponen de manifiesto que los pertrechos de la imprenta mancomunada quedaron en la Trapería y, por tanto, en manos de Muñiz, quien siguió trabajando en ella y pronto ampliaría su actividad a Cartagena. Posiblemente, desde 1795 pasara a gestionar el taller de Marina compatibilizando así el trabajo de ambas oficinas, lo que le permitiría no sólo subsistir sino adquirir un cierto desahogo económico. Como impresor de la Real Armada seguiría imprimiendo en la ciudad hasta su muerte en 1804 en que la viuda y el hijo asumirían el conreo del taller de la Trapería.

Por su lado, Santa María pasaría a abrir su propia imprenta en Orihuela, un taller que desde 1792 mantendría una actividad continuada hasta la desaparición del

${ }^{53}$ A.H.P. Murcia. Prot. 3151, ante Jiménez Pérez Rojo, 1792, f. 161 r y v. "Antonio Santa María y Manuel Muñiz, escritura de convenio y obligación”. 
impresor en torno a 1810. Del mismo modo que ocurriera con su antiguo socio, Manuela Navarro, su viuda, permanecería al frente de la consolidada oficina oriolana hasta 1819 , fecha en que madre e hijo volverían de nuevo a la ciudad del Segura.

\section{CONCLUSIÓN}

Una vez desgranados los datos contenidos en las distintas escrituras podemos sintetizar algunos puntos sobre las circunstancias que rodearon el destino final de la imprenta Cayuelas y la situación que hubieron de afrontar dos conocidos nombres de la tipografía murciana.

En cuanto a la primera cuestión, la imprenta del Plano de San Francisco vivirá una última etapa tipográfica mediante su arrendamiento a Antonio de Santa María, un maestro venido de Orihuela. Para entonces, la conocida imprenta había pasado a ser un establecimiento de tercera fila repleto de aparejos, en su mayoría reciclados, pero carente de las imprescindibles fundiciones. Después de varios años cerrada, su puesta en funcionamiento en la década de los años 80 exigió una fuerte inversión económica que, sin embargo, no lograría hacerla rentable. Este hecho queda patente a través de la escasez de trabajos tipográficos conservados y de los problemas económicos sufridos por su arrendatario.

En segundo lugar, la formación de una compañía por parte de los impresores Santa María y Manuel Muñiz pone en evidencia la necesidad de aunar recursos en la consecución del fin perseguido: la puesta en marcha de una nueva oficina tipográfica. El breve recorrido de la imprenta mancomunada, tan sólo cuatro años, debe ser entendido dentro de un contexto caracterizado por la atonía del mercado local y la escasez de trabajo impresor suficientemente cubierto por las oficinas ya existentes. A esto hay que sumar la descapitalización de los asociados. Son maestros de imprenta emprendedores, conocedores de su oficio, pero carentes de bienes propios, con escaso patrimonio familiar y que se verán obligados a utilizar la vía crediticia en el desarrollo de sus planes. Finalmente, los pleitos, las deudas y la competencia harían inviable su supervivencia.

Nos gustaría hacer una última consideración con objeto de poner de relieve la trascendencia que, para componer la historia y rescatarla de la fabulística tradicional, tienen los hallazgos documentales con la localización de escrituras de la más variada tipología. Ciertamente, los impresores protagonistas de esta historia eran ya conocidos por los estudiosos de la imprenta murciana, pero se trataba de un conocimiento limitado, basado en suposiciones carentes, en la mayoría de las ocasiones, de fundamento. Esto es debido a que las fuentes de información manejadas casi en exclusiva han sido las portadas de los impresos que, evidentemente, dan noticia de determinados hechos (asociación de los impresores) o aportan algunos indicios que pueden orientar la investigación (localización de la imprenta o años de impresión). Dichas fuentes bibliográficas no son suficientes y no permiten dar razones, contestar preguntas, analizar acontecimientos, establecer relaciones, etc. 
Todas estas cuestiones pueden ser abordadas como se ha visto desde los datos contenidos en protocolos notariales, actas y legajos municipales y los siempre recurrentes libros parroquiales.

\section{BIBLIOGRAFÍA}

BURGOS, F. X. y PEÑA DÍAZ. M. "Imprenta y negocio del libro en la Barcelona del siglo XVIII. La casa Piferrer". Manuscrits: Revista d'història moderna, 1987, 6: 181-216.

CANDEL CRESPO, F. "Don Luis Muñiz y Casajuz (1788-1860), sacerdote y periodista murciano". Anales de Historia Contemporánea. Universidad de Murcia, 1983, 2: 63-80.

CORBETO, A. Eudald Pradell y la fundición del convento de San José. [en línea] [consulta: 20 abril 2011] [disponible en: www.unostiposduros.com.] [Texto presentado en el Primer Congreso Internacional de Tipografía, Valencia 2004].

FRANCH, R. y MESTRE, A. "La compañía de Impresores y Libreros de Valencia: finanzas y cultura en el siglo XVIII. Revista de Historia Moderna. Anales de la Universidad de Alicante, 1984, 4: 23-46.

GARCÍA CUADRADO, A. "La Compañía de Mercaderes de la Corte a mediados del siglo XVIII". Anales de Documentación, Universidad de Murcia, 2001, 4: 95-126.

GARCÍA CUADRADO, A. "Los Royo en la Murcia del siglo XVIII: apuntes sobre librería y conflictos entre libreros". Carthaginensia, 2009, 48: 407-437.

GARCÍA CUADRADO, A. "Cesión del privilegio de impresión de libros doctrinales para el Reino de Murcia". Tejuelo, Revista de Anabad-Murcia, 2009, 9: 36-45.

ITUURBIDE DÍAZ, J. Escribir e imprimir. El libro en el Reino de Navarra en el siglo XVIII. Pamplona: Gobierno de Navarra; Institución Príncipe de Viana, 2007, 445 p.

LARRUGA Y BONETA, E. Memorias políticas y económicas sobre los frutos, comercio, fábricas y minas de España: con inclusión de los reales decretos, órdenes, cédulas..., tomo III. Madrid: Espinosa, 1788.

MOLL ROQUETA, J. "El taller de la imprenta". En: Historia de la edición y de la lectura en España 1472-1914. Madrid: Fundación Germán Sánchez Ruipérez, 2003, p. 481-490.

Murcia 1756 Según las Respuestas Generales del Catastro de Ensenada. Introducción de Guy Lemeunier. Madrid: Ediciones Tabapress, 1993, 332 p.

NIETO SÁNCHEZ, J. A. Artesanos y mercaderes: una historia social y económica de Madrid (1450-1850). Madrid: Taller de Historia Social; Editorial fundamentos, 2006, $493 \mathrm{p}$. 